\title{
Der Atlas der ungarischen Dialekte in Rumänien steht vor der Vollendung
}

\author{
Dezsö Juhász, Erika Terbe \\ Eötvös Loránd Tudományegyetem, Magyar Nyelvtudományi és Finnugor Intézet, \\ H-1088 Budapest, Múzeum krt. 4/A, \\ juhasz.dezso@btk.elte.hu,terbe.erika@btk.elte.hu
}

\section{SCN III/1 [2010], 61-73}

Enajsti, zadnji del Atlasa madžarskih narečij v Romuniji (The Atlas of Hungarian Dialects in Romania - RMNyA) je pripravljen za tisk. Delo, za katerega so gradivo zbirali v petdesetih in šestdesetih letih 20. stoletja, pomembno zaokrožuje madžarsko dialektologijo. RMNyA omogoča podrobnejši opis madžarskih narečij v Romuniji in njihovo pregledno tipologijo. Odpira nove možnosti za sinhrone in diahrone preglede. Sočasno z izdajo je bil RMNyA uvrščen v projekt za digitalizacijo MNyA, rezultat tega pa je integracija dveh velikih atlasov v eno samo elektronsko bazo podatkov. To omogoča nove lingvistične in narečne analize korpusa kot tudi pripravo integriranih map z uporabo računalniške kartografije.

The $11^{\text {th }}$ and last volume of The Atlas of Hungarian Dialects in Romania (RMNyA) is ready for publication. The work, the material of which was gathered in the 1950s and 1960s, is suppletory in Hungarian dialectology. The RMNyA enables a more detailed description of the Hungarian dialects in Romania and a comprehensive typology of dialects. It opens new possibilities for synchronic and diachronic examinations. Concurrently with its publication, the RMNyA was included in the project for the digitalisation of the MNyA, as a result of which the two big atlases are integrated into a single electronic database. This enables new corpus linguistical and dialectological analyses as well as the preparation of integrated maps by using the techniques of computer cartography.

Ključne besede: madžarska narečja v Romuniji, jezikovni atlas, geolingvistika, inkorporacija atlasov, digitalizacija

Key words: Hungarian dialects in Romania, linguistic atlas, geolinguistics, incorporation of atlases, digitisation 
1 Der 11. und letzte Band des Atlas der ungarischen Dialekte in Rumänien (RMNyA) steht vor der Veröffentlichung. Das Werk, dessen Material in den 1950er und 1960er Jahren gesammelt wurde und seit 1995 veröffentlicht wird, schließt eine Lücke in der ungarischen Dialektologie. Mit 136 Forschungspunkten und 3300 Karten ist er eine bedeutende Ergänzung des aus Rumänien stammenden Materials des Atlas der ungarischen Dialekte (MNyA), dessen Sammlung in den 1950er Jahren aus politischen Gründen nicht abgeschlossen werden konnte. Die Budapester Sprachwissenschaftler konnten ihre Erhebungen nur an 22 Sammelpunkten in Siebenbürgen durchführen. Die Veröffentlichung des RMNyA ermöglicht eine detailliertere Beschreibung der ungarischen Dialekte in Rumänien sowie die Erstellung einer umfassenden Dialekttypologie. Es ergeben sich - unter anderem - neue Möglichkeiten für synchrone und diachrone sprachgeografische und siedlungsgeschichtliche Untersuchungen des gesamten Sprachraums.

Zeitgleich mit der Veröffentlichung wurde der RMNyA in das Projekt zur Digitalisierung des MNyA einbezogen. Die beiden großen Atlanten sollen zu einer einzigen elektronischen Datenbank verschmelzen - die nach und nach auch durch kleinere regionale Atlanten ergänzt werden soll. Dadurch werden neue korpuslinguistische und dialektologische Analysen möglich, und mithilfe der Computerkartografie können auch synthetisierende Karten erstellt werden. Der RMNyA ist also auch für vergleichende Untersuchungen mit kleineren und größeren Atlanten geeignet. Die sprachliche Grundlage für umfassende Analysen unter Einbeziehung mehrerer Atlanten sind einerseits die mit einheitlichen Stichwörtern versehenen Karten und andererseits die mit unterschiedlichen Stichwörtern versehenen, aber identische dialektologische Phänomene darstellenden Karten der untersuchten Atlanten.

An ausgewählten Forschungspunkten des MNyA und des RMNyA finden auch Untersuchungen zur Gegenwartssprache mit einem aus den gemeinsamen Fragen der beiden Atlanten bestehenden Fragebogen statt. Mit diesen sollen der synchrone Sprachzustand erhoben und außerdem die sprachlichen Veränderungen der letzten 50 Jahre ermittelt werden. An einzelnen Phasen dieser Arbeiten nehmen die Rumänische Akademie der Wissenschaften, die Ungarische Akademie der Wissenschaften, die Ungarische Gesellschaft für Sprachwissenschaft und die Eötvös-Loránd-Universität Budapest teil.

2 Nach dieser allgemeinen Einführung werden nun einige Einzelheiten vorgestellt. Im ersten Teil des Vortrags geht es um die Sammelarbeit und die Arbeiten im Zusammenhang mit der Veröffentlichung des RMNyA, im zweiten Teil dann um die Verwendung des Werkes und um den Prozess, durch den der Atlas in die modernen sprachgeografischen Forschungen integriert wird.

Das erste wichtige Datum in der Geschichte des Atlasses war das Jahr 1955, als die Klausenburger Abteilung des Sprachwissenschaftlichen Instituts der Rumänischen Akademie der Wissenschaften die sprachgeografische Untersuchung der ungarischen Dialekte Rumäniens in sein Forschungsprogramm aufnahm. Mit der Leitung der Arbeiten wurde Professor Attila T. Szabó, ein 
anerkannter Vertreter der siebenbürgischen Sprachwissenschaft, beauftragt. Die Arbeitsgruppe, die hierfür zusammengestellt wurde, wurde jedoch von der politischen Diktatur der Zeit innerhalb weniger Jahre aufgelöst. 1959 war nur noch eine einzige Person, der Forscher László Murádin, mit der Fortsetzung der Sammelarbeit und der Erstellung des Manuskripts des Atlasses befasst. Somit führte er die Arbeiten, für die ursprünglich drei Personen vorgesehen waren, alleine aus - was eine außerordentliche persönliche Leistung war. Von den geplanten 220 Forschungspunkten blieben nur 136 übrig, doch auch diese Anzahl ist proportional repräsentativ für die ungarischen Dialekte in Rumänien. (Zur Vergleichung siehe die Anzahl von Vorschungspunkten: MNyA: 395, RMNyA: 136, und von Karten: MNyA: 1162, RMNyA: 3300 Hier ist anzumerken, dass der Fragebogen für den RMNyA auch die Fragen des MNyA enthält.)

Und all das haben wir der unermüdlichen Sammelarbeit eines einzigen Menschen zu verdanken, der das vielfältige Dialektmaterial außerordentlich präzise und zuverlässig erfasst hat. Die intensive Feldarbeit dauerte von 1957 bis 1967, dann folgte das Ordnen der Daten, das ebenfalls etwa zehn Jahre in Anspruch nahm. Dabei entstand nicht nur eine nach Fragen und Forschungspunkten geordnete Zettelsammlung, sondern auch ein Manuskript mit 1200 Karten. Die Nationalitäten- und Wissenschaftspolitik der Ceauşescu-Ära bedeutete jedoch erneut ungünstige Umstände für die Fortsetzung der Arbeit: An eine Veröffentlichung der Karten, die Rückschlüsse auf die ethnischen Verhältnisse zuließen, war ab der zweiten Hälfte der 1970er Jahre überhaupt nicht zu denken. Deshalb ersann man eine Kompromisslösung: solange die Veröffentlichung der Karten nicht möglich war, sollte eine sprachgeografische Datensammlung entstehen, in der die auf den Zetteln festgehaltenen Daten in der Art eines Wörterbuches, aber in der Reihenfolge des Fragebogens aufgelistet werden sollten. Das entsprechende Manuskript mit einem Umfang von über zweitausend Seiten wurde dann auch innerhalb weniger Jahre erstellt, doch auch dieses konnte nicht veröffentlicht werden.

Dieser Teil des Ordnens der Daten war jedoch nicht vergeblich, da er die spätere Archivierung und Kartografierung, die bereits elektronisch vorgenommen wurde, sehr erleichterte. Doch bis dahin mussten eineinhalb Jahrzehnte der Aussichtslosigkeit vergehen. Die Wende brachten die Regimewechsel in Osteuropa, die zwar die materiellen Umständen für wissenschaftliche Projekte nicht verbesserten, aber die diktatorischen Verhältnisse, die auch in der Wissenschaftspolitik herrschten, zum großen Teil abschafften. Auch diesem Umstand ist es zu verdanken, dass das Manuskript des RMNyA nach Budapest gelangte, wo mittels einer Ausschreibung der Ungarischen Gesellschaft für Sprachwissenschaft und durch die Mitwirkung der Forscher der Eötvös-Loránd-Universität die benötigte materielle und fachliche Infrastruktur für die Publikation aufgestellt werden konnte. Die Leitung der 1993 eingerichteten Forschungsgruppe und die redaktionellen Aufgaben des Atlasses übernahm Dezső Juhász.

3 Der erste Band des RMNyA erschien im Jahr 1995, der zehnte verließ im Jahr 2006 die Druckerei. Jeder Band enthält durchschnittlich 300 Karten und 
am Ende einen kurzen Wörterbuchteil. Dieser besteht aus Einträgen, zu denen (wegen der großen Übereinstimmung der Daten) keine gesonderten Karten erstellt wurden. Alle Karten wurden nach der Methode der Dateneintragung erstellt, das heißt, bei den einzelnen Forschungspunkten werden die auf die gestellten Fragen erhaltenen Antworten in genauer phonetischer Umschrift angegeben. Außerdem enthalten die lexikalischen und morphologischen Karten vor den einzelnen Wörtern verschiedene Symbole - zum Beispiel Kreise, Vierecke, Dreiecke oder Rhomben -, die die räumliche Verteilung der Wörter darstellen. Der Umstand, dass die Antworten in der Datensammlung des Manuskripts bereits nach lexikologischen und morphologischen Kriterien geordnet waren, hat die Eintragung der grafischen Symbole erheblich erleichtert. (Diese Art der Darstellung der außerordentlich vielfältigen phonetischen Verteilung war in der gedruckten Version des Atlasses nicht möglich.)

Im Vergleich zu den früheren, von Hand gezeichneten Karten hat der Einsatz von Computern nicht nur dazu geführt, dass die Karten schöner und eleganter sind, sondern auch den Ausbau der sprachgeografischen Datenbanken ermöglicht. In den mit dem Textverarbeitungsprogramm Word erstellten Wörterbucheinträgen konnte die phonetische Umschrift mit ihren vielen diakritischen Zeichen sehr gut wiedergegeben werden, für die elektronische Arbeit mit der Dialektphonetik (zum Beispiel verschiedene Suchaufgaben) waren sie jedoch - wie sich später herausstellte - nur eingeschränkt geeignet. Deshalb hat es sich die Arbeitsgemeinschaft an unserer Universität auch zur Aufgabe gemacht, die Daten der mit der traditionellen Technik und der bereits elektronisch erstellten Atlanten in einer Datenbank mit einer einheitlichen Struktur und Technik zusammenzuführen. (Davon wird im zweiten Teil des Vortrags noch die Rede sein.)

4 Und nun zu den wichtigsten formalen Merkmalen der gedruckten Version des RMNyA.

Die Karten werden - anders als beim MNyA - nicht als Einzelblätter in Boxen, sondern zu einem Buch gebunden herausgegeben. Die Karten nehmen jeweils eine linke und eine rechte Seite des Buches ein. So konnte das rechteckige Sammelgebiet auf genormten Seiten des Formats A3 abgebildet werden, ohne die Daten gedrängt darzustellen. In der linken oberen Ecke befindet sich der sogenannte Kopf (die Legende), der folgende Informationen enthält: 1. die laufende Nummer der Karte, 2. das Stichwort, 3. seine Bedeutung auf Rumänisch und Französisch, 4. die Frage des Fragebogens und ihre Nummer sowie 5. Anmerkungen (soweit erforderlich, mit sachlichen oder individuellen dialektologischen Informationen). Die Fragen des Fragebogens können auch durch Zeigen oder durch Zeichnungen ersetzt werden. Die Zeichnungen weniger gängiger Gegenstände sind in der rechten oberen Ecke der Karte abgebildet.

In den phonetischen Karten wurden - wie bereits erwähnt - lediglich die Daten eingetragen, die lexikalischen Karten enthalten auch Symbole. Wenn in einer Karte eine lexikalische Variante überwiegt, wird diese nicht gekennzeichnet, die Nebenformen erhalten jedoch eine grafische Markierung. Wenn 
es keine dominante Form gibt, wird jede Variante mit einem Symbol versehen. Varianten, die nur einmal genannt wurden, sind einheitlich mit einem Stern $\left({ }^{*}\right)$ gekennzeichnet. Das Zeichen für eine fehlende lexikalische Einheit ist das Minus (-), Lücken in den gesammelten Daten sind durch leere Stellen markiert. - Das sprachgeografische Wörterbuch folgt dem beschriebenen Aufbau. (Die Stichwörter des Fragebogens wurden in Einzelfällen geändert, und zwar wurden abweichende Formen entweder den Stichwörtern des MNyA oder der Gemeinsprache angeglichen.) Die in den Karten verwendeten grafischen Symbole dienen in den Einträgen der Gliederung; die Reihenfolge der lexikalischen Realisationen entspricht ihrer Häufigkeit. Die durch Symbole getrennten Einheiten bilden auch die Grundlage für die spätere Bestimmung der Verweise. Wenn die Veröffentlichung des RMNyA mit dem 11. Band abgeschlossen ist, möchten wir das integrierte sprachgeografische Wörterbuch oder das detaillierte Wörterverzeichnis der beiden großen Atlanten veröffentlichen oder ins Internet stellen.

5 Für welche Bereiche ist die Veröffentlichung des RMNyA unentbehrlich, und in welchen kann sie zu grundlegend neuen wissenschaftlichen Ergebnissen führen? Hier ist an erster Stelle die Systematisierung der Dialekte, die Dialekttypologie, zu nennen. In der ungarischen Dialektologie gibt es zwar eine umfassende Synthese, die auf dem Material des Atlas der ungarischen Dialekte basiert (Samu Imre: Das System der ungarischen Dialekte der Gegenwart [A mai magyar nyelvjárások rendszere]. Budapest, 1971), doch diese Monografie enthält gerade zum ungarischen Sprachgebiet in Rumänien lediglich einen skizzenhaften Überblick, da vor dem Abbruch der Arbeiten, wie bereits erwähnt, nur die Daten von 22 Forschungspunkten gesammelt werden konnten. Nach Imres Vorbild soll das noch zu verfassende Werk den Titel Das System der ungarischen Dialekte in Rumänien [A romániai magyar nyelvjárások rendszere] tragen. Die Grundlage für die neue Monografie können die Karten sein, die anhand der integrierten Datenbank der beiden Atlanten erstellt werden können. (Die Integration der Atlanten betrifft zum einen konkrete Karten und zum anderen bestimmte phonetische und morphologische Grundphänomene.) Auch Imres Monografie enthält synthetisierende phonetische, phonologische und morphophonologische Karten, diese wurden jedoch noch „manuell“, das heißt, durch eine Verarbeitung der Daten von Hand nach der Zettelmethode, erstellt und auch von Hand gezeichnet. Die elektronischen sprachgeografischen Datenbanken sind natürlich als Grundlage nicht nur für die monografische Besprechung der Dialekte als solcher geeignet, sondern auch für die Besprechung einzelner Gruppen von Phänomenen (zum Beispiel phonologischer oder morphologischer Systeme).

Monografisch aufgearbeitet werden können auch die einzelnen Forschungspunkte, denn die mehr als 3300 Karten bieten eine Vielzahl von Beispielen für eine komplexe Besprechung. Besondere Aufmerksamkeit verdienen die Dialektinseln, die mit ihren Archaismen und Neologismen wahre Fundgruben der Dialektologie und der Sprachgeschichte sind und zudem wertvolle Anhalts- 
punkte für die Bevölkerungsbewegungen in den verschiedenen Epochen der ungarischen Siedlungsgeschichte bieten. Mit der Geschichte und der Migration der ethnischen Gruppen der Szekler und der Tschangonen haben sich auch bisher viele Forscher befasst, doch die vergleichenden sprachgeografischen Forschungen können noch zur Klärung zahlreicher Detailfragen beitragen (vergleiche zum Beispiel Juhász 2004b). Da wir für diese Gegenden auch regionale Sprachatlanten haben (siehe zum Beispiel MCsNyA), können integrierte Untersuchungen auch hier im Mittelpunkt stehen. Von der Gegend Mezőség in Siebenbürgen hingegen wurde kein regionaler Atlas erstellt, sodass die diesbezüglichen Daten des RMNyA einer ersten Erschließung gleichkommen.

6 In dem folgenden wissenschaftsgeschichtlichen Überblick möchten wir auf einige Publikationen aus der Fachliteratur zu den Dialekten in Siebenbürgen und in der Moldau hinweisen, die in mehr oder weniger engem Bezug zu unserem Atlas stehen.

Im ungarischen Sprachraum wurden Untersuchungen zu den Dialektkarten als Erstes in Bezug auf Siebenbürgen vorgenommen (siehe Szabó T. 1957: 14). Als erstes wichtiges Ergebnis aus der Zeit vor dem Zweiten Weltkrieg ist hier der Artikel von Antal Horger von 1905 zu nennen (Horger 1905: 446-454 + Karte). Er stellte anhand seiner fünfjährigen Sammelarbeit, die alle Ortschaften der Ostszekler umfasste, einige phonetische und morphologische Merkmale auf einer einzigen Karte dar. Relativ umfangreiche Daten von fünf ungarischen Forschungspunkten wurden außerdem im Rumänischen Sprachatlas (Atlasul Linguistic Român 1-2.) festgehalten. In diesem Atlas wurde auch die erste ungarische sprachgeografische Sammlung veröffentlicht (Bárczi 1955: 18-19).

Als László Murádin vor der Veröffentlichung des ersten Bandes des Atlasses die Liste der Abhandlungen über die Arbeiten zum Atlas und über die Besprechung der Daten im Manuskript zusammenstellte, erhielt er eine Aufstellung mit mehr als sechzig Titeln. Ein Großteil dieser Arbeiten waren Publikationen von Murádin selbst, die in den Klausenburger Mitteilungen zur Sprach- und Literaturwissenschaft erschienen waren. Hier können nur einige Titel - ohne die genauen Fundstellen - genannt werden; die detaillierten Angaben enthält das einleitende Kapitel des 1. Bandes (RMNyA 1: 17-18).

Ph on et i k: „Eine Konsonantenveränderung in der Gegend Mezőség“'[Egy mezőségi mássalhangzó-változás]; „,Der Unterschied zwischen den Phonemen $e$ und $\ddot{e}$ und seine Verteilung in den ungarischen Dialekten in Rumänien“ [Az e/ë fonémakülönbség megléte és megoszlása a romániai magyar nyelvjárásokban]; „Die Verbreitung des assoziativen $a$ in den ungarischen Dialekten in Rumänien“" [Az asszociatív $\dot{a}$-zás elterjedtsége a romániai magyar nyelvjárásokban]; ,Die Verbreitung des Ersetzens durch $i$ (i) in Siebenbürgen“ [Az $i$ (i)-zés erdélyi elterjedtsége]; „Das Verhältnis zwischen $e$ und $\ddot{o}$ im Mezőséger Dialekt“ [Az e/ö hangviszony a mezőségi nyelvjárásban]; „Das Ersetzen durch $a$ in der Gegend Mezőség“ [A mezőségi $a$-zás]; ,,Der Wechsel zwischen $n y$ und $n$ am Ende des Wortstamms in den ungarischen Dialekten in Rumänien" [A tővégi ny : $n$ váltakozás a romániai magyar nyelvjárásokban] usw. - M o r p h e mat i k: 
„Eine Gruppe der Verben mit $v$ am Ende des Wortstamms in den ungarischen Dialekten in Rumänien“ [A $v$ tövü igék egy csoportja a romániai magyar nyelvjárásokban]; „Die Funktion der Adverbialsuffixe -ni, -nitt, -nul, -nül und ihre Verbreitung in Siebenbürgen" [A -ni, -nitt, -nul, -nül határozórag-csoport funkciója és erdélyi elterjedtsége]; „Die Lautform und die Entwicklung des Verbalsuffixes -it in den siebenbürgischen Dialekten“ [Az -ít igeképző erdélyi nyelvjárási hangalakja és alakulásmódja]; „Die „suksük“-Sprache in den siebenbürgischen Dialekten“ [A „suksük nyelv“ az erdélyi nyelvjárásokban] usw. - L ex i k, Wort s e mant i k: „Sprachgeografische Daten zum Wortschatz der Wiesenwirtschaft der ungarischen Bauern" [Nyelvföldrajzi adatok a magyar parasztság rétgazdálkodásának szókincséhez]; „Zu den inneren und arealen Relationen der Bezeichnungen von Gebäuden für die Haustierhaltung “ [Háziállatok tartására szolgáló épületek neveinek belső és területi összefüggéseihez]; „Siebenbürgische Sprachgeografie der Wörter zum Rufen und Verscheuchen von Tieren“ [Állathívogató és -űző szavak erdélyi nyelvföldrajza]; „Die Gliederung des Bedeutungsfeldes und die Dialektisoglossen“ [A jelentésmezö tagolása és a nyelvjárási izoglosszák]; „Die Bedeutung von ellik [Junge bekommen] und der mit diesem bedeutungsverwandten Wörter" [Az ellik és rokon értelmü társainak jelentésköre]; „Die Gliederung des Bedeutungsfeldes 'Person, die das Eigentum hütet' in den ungarischen Dialekten in Rumänien" [A 'tulajdont őrző személy’ jelentésmező tagolása a romániai magyar nyelvjárásokban]; usw.

Die lexikalischen und semantischen Untersuchungen bieten sich für in terdisziplinäre Studien an, insbesondere für Bezüge zur Ethnografie. Zum Thema Ackerbau und Tierhaltung sind Abhandlungen wie die folgenden zu nennen: „Aus dem Dialektwortschatz für den Wagen und seine Teile“ [A szekér és részeinek nyelvjárási szókincséből]; „Sprachgeografische Daten zum Wortschatz des Ackerbaus mit dem Pflug" [Nyelvföldrajzi adatok az ekés földművelés szókincséhez]; „Sprachgeografische Daten zum Wortschatz des kukorica [Mais]“ [Nyelvföldrajzi adatok a kukorica szókincséhez]; „Die Bezeichnungen des Zaunes und seiner Varianten in den ungarischen Dialekten in Siebenbürgen“ [A kerítés és fajtáinak megnevezései az erdélyi magyar nyelvjárásokban]. Von einem erweiterten Blickfeld zeugen Titel wie „Aus dem Dialektwortschatz der Insektennamen“ [A rovarnevek nyelvjárási szókincséből]; „Die siebenbürgische Sprachgeografie der Bezeichnungen für einige Niederwildarten“ [Néhány apróvad neveinek erdélyi nyelvföldrajza] usw.

Nach dem Erscheinen des ersten Bandes begannen auch die an der Veröffentlichung des Atlasses Beteiligten mit der Publikation von Abhandlungen über die Daten. (Wegen des beschränkten Umfangs werden hier statt Titeln nur noch Themenbereiche genannt.)

Dezső Juhász, der Leiter der Arbeitsgruppe, hat die s p r a c h g e s c h i c h tlichen, namenkundlichen sowie volkstums-und siedlungsgeschichtlichen Aspekte untersucht: In der Zusammenfassung der Publikationsgeschichte des RMNyA ergänzt er die sprachwissenschaftlichen Analysen durch wissenschaftsgeschichtliche Hintergrundinformationen und zeigt die anhand der Karten des Atlasses gewonnenen sprachlichen und sied- 
lungsgeschichtlichen Erkenntnisse auf (Juhász 1997, 2006). Die Bände des Atlasses enthalten eine ganze Reihe von Eigennamen und geografischen Namen, und zwar in ihrer Grundform ebenso wie in flektierter Form. Bei den Personennamen und den Diminutiv- und Koseformen von Personennamen liefert zumeist das familiäre Ortsbestimmungssuffix, bei den Ortsnamen die Formen mit Inessiv- oder Sublativsuffix wichtige Informationen für die Namenkunde (Juhász 1999: 395-400). Die sprachgeografischen Veröffentlichungen können, ja müssen auch für sprachgeschichtliche Forschungen genutzt werden, da die Namen der Ortschaften am Rand des Sprachgebiets zahlreiche Archaismen und Neologismen aufweisen. Die Atlanten enthalten viele Paradigmen der - $i k$-Konjugation, und die entsprechenden Karten zeigen verschiedene Phasen der Entstehung einiger ungarischer Suffixe. In einigen Fällen ermöglichen die Karten die Ergänzung und die Präzisierung sprachgeschichtlicher Feststellungen, so zum Beispiel hinsichtlich der Etymologie des Wortes hurok [Schlinge] (Juhász 2000: 209-212).

Auch die Erkenntnisse über die umstrittene Geschichte der Tschangonen und die Herkunft der Nordtschangonen wurden durch den Atlas erweitert (Juhász 2003: 41-46, 2004b: 163-174). Mit weiteren Zusammenhängen befasst sich die Abhandlung „Der Atlas der ungarischen Dialekte in Rumänien als Enzyklopädie der traditionellen Kultur und der Volkssprache in Siebenbürgen“ (Juhász 2004a: 233-237).

Erika Terbe hat die Zusammenhänge zwischen der Wortsemantik und der Sprachgeografie untersucht, beispielsweise anhand der Karten für die Wörter örvény 'Wirbel, Strudel' und kényes 'empfindlich, heikel', sowie die Erkenntnisse aus der integrierten Nutzung von Sprachatlanten anhand der Karte für gyáva 'feige' dargelegt (Terbe 1999, 2003a, 2003b, 2006).

Auch in der Ph.-D.-Dissertation von Andrea Hegedüs geht es um den RMNyA. Sie bespricht in ihrer Arbeit die theoretischen, methodischen und technischen Fragen der - vor allem elektronischen - Integration der ungarischen Dialektatlanten und hat unter Verwendung integrierter Sprachkarten sprachgeografische Analysen für den östlichen Teil des ungarischen Sprachgebietes vorgenommen.

Die Themenwahl der Dissertation weist auf eine besondere Situation hin: Als der Atlas der ungarischen Dialekte (MNyA), der den gesamten ungarischen Sprachraum umfasst, erschien, rechneten die Forscher damit, dass dieses hervorragende Quellenwerk in der ungarischen Dialektforschung zum größten Aufschwung aller Zeiten führen würde, diese Hoffnung wurde jedoch nicht beziehungsweise nur zum Teil erfüllt. Die Gründe dafür sind unter anderem, dass 1. die Fachleute, die die Karten interpretieren können, wegen anderweitiger Aufgaben nur wenig Zeit für die Sprachgeografie aufwenden können, 2. in der jüngeren Generation vorerst nur wenige über das interdisziplinäre Wissen verfügen, das erforderlich ist, um die Karten „zum Sprechen zu bringen“, und 3. ein Überblick über die Ansammlung von mehreren Zehntausend oder gar Hunderttausend Daten, die Arbeit mit diesen, ihre Gruppierung usw. heute mit herkömmlichen Mitteln, also ohne den Einsatz von Computern, sehr umständlich ist. 
Die Idee, die Atlanten zu integrieren und zu digitalisieren, ist auf folgende Umstände zurückzuführen (Hegedüs 2008; Bodó - Vargha 2008):

1. Obwohl sie in der wissenschaftlichen Forschung jeweils unterschiedlichen Zwecken dienen, ergänzen sich die Großatlanten und die regionalen Atlanten sehr gut.

2. Einige Atlanten sind so schwer oder groß, dass sie sehr umständlich zu handhaben sind.

3. Bei regionalen Atlanten, die von ein und demselben Sammler oder Herausgeber stammen, versteht sich die Integration sozusagen von selbst; siehe zum Beispiel die Atlanten der Arbeitsgemeinschaft an der Universität Klausenburg (Cluj-Napoca) über die Moldauer Tschangonen (MCsNyA) und über die Szekler (noch in Manuskript) oder die regionalen Atlanten von Olga Penavin über die Gegenden des ehemaligen Jugoslawien (insgesamt 6 Atlanten).

4. Die Speicherung und Bearbeitung von mehreren Zehntausend oder Hunderttausend Daten ist heute ohne Computer sehr umständlich.

5. Die Idee der Integration der Atlanten passte auch zu der sprachtechnologischen Entwicklungsarbeit, die seit den 1990er Jahren am Seminar für Ungarische Sprachgeschichte, Soziolinguistik und Dialektologie der EötvösLoránd-Universität erfolgt.

6. Die Anregung, ein digitales Dialektwörterbuch (oder mehrere) zu erstellen, hat zur Weiterentwicklung der Idee der Integration der Atlanten geführt.

7 Die Arbeiten zur Veröffentlichung des Atlas der ungarischen Dialekte in Rumänien nähern sich dem Ende, damit ergeben sich jedoch auch Möglichkeiten für die nächsten Schritte. Am Seminar für Sprachgeschichte, Soziolinguistik und Dialektologie der Eötvös-Loránd-Universität laufen auch weiterhin geolinguistische Forschungsprojekte über den ungarischen Sprachraum in Rumänien. Eines davon umfasst die Veröffentlichung des letzten Bandes des RMNyA und die Integration der Stichwörter aller elf Bände (im Rahmen einer Ausschreibung der Ungarischen Gesellschaft für Sprachwissenschaft; Leiter des Projekts ist Dezső Juhász).

Das Ziel eines anderen Programms unter der Leitung von Katalin Fodor besteht darin, die Dialekte möglichst vieler Ortschaften der Moldauer Tschangonen so umfassend wie möglich zu erfassen, um aus den von Studenten gesammelten Daten ein eigenständiges Korpus zu erstellen. (Näheres zur Sammelarbeit und zum ursprünglichen Konzept siehe in Fodor 2004).

Auch Csanád Bodó hat Forschungen über die Sprachgemeinschaft der Moldauer Tschangonen durchgeführt und betreibt diese auch weiterhin. Dabei verwendet er unter anderem verschiedene Modelle der sprachlichen Sozialisation und der sprachlichen Planung (Bodó 2004, 2007).

Die dem Seminar angegliederte Werkstatt für Geolinguistik hat in den letzten Jahren an mehreren sprachgeografischen Projekten gearbeitet. Im Rahmen eines dieser Projekte wurden die ersten fünf „Bände“ der CD-ROM Reihe „Hörbuch der ungarischen Dialekte“ (Hajdú et alii 2005-2008) erstellt. Bei einem 
anderen wurden der Plan von Lajos Balogh und Gábor Kiss zur Digitalisierung des MNyA weitergeführt (vgl. Balogh - Kiss 1992 und den Internetauftritt der Werkstatt unter http://geolingua.elte.hu), das Material der Kontrollsammlung aufgearbeitet und die theoretischen und methodologischen Grundlagen des Programms Olló (zur Bearbeitung von Daten zur Ortsnamengeschichte) erarbeitet (siehe http://geolingua.elte.hu; vgl. Juhász 2007: 40). Einen weit gefassten Überblick über die sprachwissenschaftlichen Forschungen bezüglich der Tschangonen gibt die Abhandlung von Vilmos Tánczos (siehe Tánczos 2004).

Auf der Grundlage der neuen sprachgeografischen Daten und Forschungen wurde auch mit der regelmäßigen Untersuchung der ungarischen Sprach- und Dialektinseln in Rumänien begonnen - siehe die Antrittsvorlesung von János Péntek an der Ungarischen Akademie der Wissenschaften (Péntek 2005).

Im Jahr 2007 haben unser Seminar und die Ungarische Akademie der Wissenschaften gemeinsam mit den Planungsarbeiten und dann den Sammelarbeiten für den Neuen Atlas der ungarischen Dialekte (Új magyar nyelvatlasz, ÚMNyA) begonnen. Im Zuge der longitudinalen Untersuchung wurden bereits an mehreren Forschungspunkten unseres Atlasses Daten erhoben, sodass hoffentlich schon bald mit der Ermittlung des Istzustands und der Veränderungen begonnen werden kann. (Zu den Plänen siehe Kiss 2006).

\section{BIBLIOGRAFIE}

Lajos BALOGH und Gábor KISS, 1992: A magyar nyelvjárások atlaszának számítógépes feldolgozása [Die Aufarbeitung des Atlasses der ungarischen Dialekte mit dem Computer]. Társadalmi és területi változatok a magyar nyelvben [Gesellschaftliche und regionale Veränderungen der ungarischen Sprache] Hrsg. Miklós Kontra. (Linguistica. Series A. Studia et dissertationes 9). Budapest: A Magyar Tudományos Akadémia Nyelvtudományi Intézete. 5-19.

Géza BÁRCZI (Hrsg.), 1955: A magyar nyelvatlasz munkamódszere [Die Methodik des ungarischen Sprachatlasses]. Budapest: Akadémiai Kiadó.

Csanád BODÓ, 2004: Szociolingvisztikai szempontok a moldvai magyar-román kétnyelvü beszélőközösségek kutatásában [Soziolinguistische Kriterien der Forschungen zu den Gemeinschaften der Moldauer ungarisch-rumänischen zweisprachigen Sprecher]. Magyar Nyelv 100. 347-358.

- -, 2007: A magyar nyelvi vitalitás területisége Moldvában [Die räumliche Verteilung der Vitalität der ungarischen Sprache in der Moldau]. Nyelv, területiség, társadalom [Sprache, Räumlichkeit, Gesellschaft]. Hrsg. Erzsébet Zelliger. A 14. Élőnyelvi Konferencia (Bük, 2006. október 9-11.) előadásai [Die Vorträge der 14. Konferenz zur Gegenwartssprache (Bük, 9.-11. Oktober 2006)]. (A Magyar Nyelvtudományi Társaság Kiadványai 228). 123-142.

Csanád BODÓ und Fruzsina Sára VARGHA, 2008: Régi nyelvatlaszok - új módszerek. Nyelvtechnológiai eljárások a nyelvföldrajzban [Alte Sprachatlanten - Ne- 
ue Methoden. Sprachtechnologische Verfahren in den Sprachgeografie]. Magyar Nyelv 104. 335-351.

Katalin FODOR, 2004: Csángó nyelvföldrajzi kutatás [Forschung zur Sprachgeografie der Tschangonen]. Nyelv és nyelvhasználat a moldvai csángók körében [Sprache und Sprachgebrauch bei den Moldauer Tschangonen] Hrsg. Jenő Kiss. (A Magyar Nyelvtudományi Társaság Kiadványai 221). 97-104.

Mihály HAJDÚ et alii 2005-2008: Magyar Nyelvjárási Hangoskönyv. I-V. [Hörbuch der ungarischen Dialekte]. CD-ROM Reihe. Budapest: Eötvös Loránd Tudományegyetem Magyar Nyelvtörténeti, Szociolingvisztikai, Dialektológiai Tanszéke.

Andrea HEGEDÜS, 2008: Nyelvföldrajzi vizsgálatok a romániai magyar nyelvterületen az egyesitett atlaszok felhasználásával [Sprachgeografische Untersuchungen im ungarischen Sprachraum in Rumänien unter Verwendung der integrierten Atlanten]. Ph.D.-Dissertation. (Unveröffentlicht)

Antal HORGER, 1905: A keleti székelység nyelvjárási térképe [Dialektkarte der Ostszekler]. Magyar Nyelv 10. 446-454 + Karte.

Samu IMRE, 1971: A mai magyar nyelvjárások rendszere [Das System der ungarischen Dialekte der Gegenwart]. Budapest: Akadémiai Kiadó.

Dezső JUHÁSZ, 1997: A romániai magyar nyelvjárások atlaszának kiadástörténeti, nyelvi és településtörténeti tanulságaiból [Publikationsgeschichtliche, sprachliche und siedlungsgeschichtliche Erkenntnisse anhand des Atlasses der ungarischen Dialekte in Rumänien]. Magyar Nyelv 93. 199-207.

--, 1999: A romániai magyar nyelvjárások atlasza névtudományi jelentőségéről [Zur namenkundlichen Bedeutung des Atlasses der ungarischen Dialekte in Rumänien]. Névtani Értesitö 21. 395-400.

- -, 2000: A hurok történetéhez, különös tekintettel a nyelvföldrajzra [Zur Geschichte des Wortes hurok \{Schlinge\}, unter besonderer Berücksichtigung der Sprachgeografie]. Magyar Nyelv 96. 209-212.

- -, 2003: A romániai magyar nyelvjárások atlaszáról, különös tekintettel a csángókra [Zum Atlas der ungarischen Dialekte in Rumänien, unter besonderer Berücksichtigung der Tschangonen]. A magyar nyelv és a magyar nyelvü oktatás helyzete Romániában [Die ungarische Sprache und der ungarischsprachige Unterricht in Rumänien]. Hrsg. Zsuzsanna Kispéter Horváthné. (A Magyar Nyelvtudományi Társaság Kiadványai 218). Budapest. 41-46.

- -, 2004a: A romániai magyar nyelvatlasz mint a hagyományos kultúra és az erdélyi népnyelv enciklopédiája [Der Atlas der ungarischen Dialekte in Rumänien als Enzyklopädie der traditionellen Kultur und der Volkssprache in Siebenbürgen]. Apáczai Csere János emlékezete. „Én gondolkodom, azért vagyok“ [Zum Gedenken an János Apáczai Csere. „Ich denke, also bin ich“]. Hrsg. Sándor Iván Kovács. Magyar Irodalomtörténeti Társaság. 233-237.

- -, 2004b: Az északi csángók eredetéről „A romániai magyar nyelvjárások atlasza“ tükrében [Über die Herkunft der Nordtschangonen anhand des „Atlasses der ungarischen Dialekte in Rumänien“]. Nyelvvesztés, nyelvjárásvesztés, nyelvcsere [Sprachverlust, Dialektverlust, Sprachwechsel]. Hrsg. P. Lakatos, Ilona, und Károlyi, Margit. Budapest: Tinta Könyvkiadó. 163-174. 
- -, 2006: Adalékok a történeti nyelvföldrajzhoz [Beiträge zur historischen Sprachgeografie]. A mondat: kaland. Hetven tanulmány Békési Imre 70. születésnapjára [Der Satz ist ein Abenteuer. Siebzig Abhandlungen zum 70. Geburtstag von Imre Békési]. Verantwortl. Hrsg. László Vass. Szeged: JGYF Kiadó. 164-172.

--, 2007: Merre tovább, magyar nyelvföldrajz? [Wie geht es weiter in der ungarischen Sprachgeografie?] Nyelv, területiség, társadalom [Sprache, Räumlichkeit, Gesellschaft]. Hrsg. Erzsébet Zelliger. A 14. Élőnyelvi Konferencia (Bük, 2006. október 9-11.) előadásai. [Die Vorträge der 14. Konferenz zur Gegenwartssprache (Bük, 9.-11. Oktober 2006)]. (A Magyar Nyelvtudományi Társaság Kiadványai 228) Budapest. 33-43.

Jenő KISS, 2006: Egy új magyar nyelvatlasz szükséges voltáról [Über die Notwendigkeit eines neuen ungarischen Sprachatlasses]. Magyar Nyelv 102, 129-142.

MCsNyA = Mózes GÁlfFY, Gyula MÁRTON und Attila SZABÓ T (Hrsg.), 1991: A moldvai csángó nyelvjárás atlasza I-II [Atlas der Dialekte der Moldauer Tschangonen I-II]. Budapest. (A Magyar Nyelvtudományi Társaság Kiadványai. 193)

MNyA = László DEME, Samu IMRE (Hrsg.), 1968-1977: A magyar nyelvjárások atlasza I-VI. [Atlas der ungarischen Dialekte. I-VI]. Budapest: Akadémiai Kiadó.

János PÉNTEK, 2005: Magyar nyelv- és nyelvjárásszigetek Romániában [Ungarische Sprach- und Dialektinseln in Rumänien]. Magyar Nyelv 101. 406-413.

$\mathrm{RMNyA}=$ A romániai magyar nyelvjárások atlasza. $\mathrm{I}-\mathrm{X}$. [Atlas der ungarischen Dialekte in Rumänien. I-X]. Az anyagot gyüjtötte és a kéziratot összeállította: László Murádin. Szerkesztette és a kiadást előkészítő munkacsoportot irányította: Dezső Juhász [Materialsammlung und Erstellung des Manuskripts: László Murádin. Herausgeber und Leiter der für die Vorbereitung zur Veröffentlichung zuständigen Arbeitsgruppe: Dezső Juhász]. 1995-2006. Budapest: Magyar Nyelvtudományi Társaság, Pharmapress Kiadó.

Attila SZABÓ T, 1957: A Román Népköztársaság magyar nyelvjárásai nyelvtérképének előkészítése [Die Vorbereitungen zur Sprachkarte der ungarischen Dialekte in der Volksrepublik Rumänien]. Nyelv-és Irodalomtudományi Közlemények 1. 13-26.

Vilmos TÁNCZOS, 2004: A moldvai csángók nyelvészeti kutatása (1945-2004) [Sprachwissenschaftliche Forschungen bezüglich der Moldauer Tschangonen (1945-2004)]. Nyelv és nyelvhasználat a moldvai csángók körében [Sprache und Sprachgebrauch bei den Moldauer Tschangonen] Hrsg. Jenő Kiss. (A Magyar Nyelvtudományi Társaság Kiadványai 222). 208-285.

Erika TERBE, 1999: Örvény. Szemantikai és szóföldrajzi vizsgálódás [Strudel. Semantische und wortgeografische Untersuchung]. Ember és nyelv. Tanulmánykötet Keszler Borbála tiszteletére [Mensch und Sprache. Abhandlungen zu Ehren von Borbála Keszler]. Hrsg. Nóra Kugler und Klára Lengyel. Budapest: ELTE BTK Mai Magyar Nyelvi Tanszék. 314-321.

- -, 2003a: Szemantikai vizsgálat nyelvföldrajzi és történeti tanulságokkal [Semantische Untersuchung mit sprachgeografischen und historischen Erkenntnissen]. A nyelvtörténeti kutatások legújabb eredményei III. Magyar és finnugor jelentéstörténet [Die neuesten Ergebnisse der sprachgeschichtlichen Forschungen III. 
Ungarische und finnugrische Bedeutungsgeschichte]. Hrsg. László Büky und Tamás Forgács. Szeged: Szegedi Tudományegyetem Magyar Nyelvészeti Tanszék. 191-196.

- -, 2003b: Adalékok a nyelvatlaszok egyesített használatához [Zur integrierten Nutzung der Sprachatlanten]. Köszöntö könyv Kiss Jenö 60. születésnapjára [Buch als Glückwunsch zum 60. Geburtstag von Jenő Kiss]. Hrsg. Mihály Hajdú, und Borbála Keszler. Budapest: ELTE Magyar Nyelvtudományi és Finnugor Intézete und Magyar Nyelvtudományi Társaság. 490-495.

--, 2006: Kényes. Szemantikai vizsgálat nyelvföldrajzi tanulságokkal [Empfindlich, heikel. Semantische Untersuchung mit sprachgeografischen Erkenntnissen]. 101 irás Pusztai Ferenc tiszteletére [101 Beiträge zu Ehren von Ferenc Pusztai]. Hrsg. Attila Mártonfi, Kornélia Papp und Mariann Slíz. Budapest: Argumentum. 215-224.

\section{ATLAS MADŽARSKIH DIALEKTOV V ROMUNIJI PRED IZIDOM}

Enajsti, zadnji del Atlasa madžarskih narečij v Romuniji (The Atlas of Hungarian Dialects in Romania - RMNyA) je pripravljen za izid. Prvi del atlasa je izšel leta 1995, deseti leta 2006. Vsak del vsebuje povprečno 300 map in kratek slovar razdelka. Vse karte so zbrane z vnosom podatkov, tj. vsi odgovori, podani v vprašalniku, so prikazani v natančni fonetični transkripciji za vsako raziskovalno točko. Delo, za katero je bilo gradivo zbrano v petdesetih in šestdesetih letih 20. stoletja, pomembno zaokrožuje madžarsko dialektologijo. S 136 raziskovalnimi točkami in 3300 mapami predstavlja znatno razširitev gradiva iz Romunije, ki ga vsebuje Atlas madžarskih narečij (The Atlas of Hungarian Dialects (MNyA)).

Zbiranje gradiva in sestavljanje rokopisa atlasa je bilo izvedeno v težkih pogojih; od leta 1959 je bilo delo prepuščeno eni sami osebi, raziskovalcu Lászlu Murádinu. Od druge polovice sedemdesetih let 20. stoletja ni bilo nikakršne možnosti za izdajo kart, ki prikazujejo etnično distribucijo v Romuniji. Po spremembi režima v vzhodni Evropi je bilo možno prenesti prvo verzijo rokopisa s podatki za RMNyA v Budimpešto, kjer so bili s pomočjo natečaja, ki ga je razpisalo Madžarsko jezikoslovno društvo v sodelovanju z raziskovalci Univerze Eötvösa Loránda, zagotovljeni pogoji za izdajo. Dezső Juhász je postal vodja raziskovalnega tima, ustanovljenega leta 1993, in urednik atlasa. László Murádin je zbral seznam člankov o delu pri atlasu pred izidom prvega dela; našel je več kot šestdeset enot, med katerimi jih je večino napisal sam. Po izidu prvega dela so tisti, ki so sodelovali pri njegovem urejanju - Dezső Juhász, Erika Terbe and Andrea Hegedüs -, prav tako začeli objavljati članke o njem.

RMNyA omogoča podrobnejši opis madžarskih narečij v Romuniji in njihovo pregledno tipologijo. Odpira nove možnosti za sinhroni in diahroni pregled na področju lingvistične geografije in zgodovine naseljevanja. Sočasno z izidom je bil RMNyA vključen v projekt za digitalizacijo MNyA, rezultat tega pa je, da sta dva velika atlasa integrirana $v$ eno samo elektronsko bazo podatkov. To omogoča nove lingvistične in dialektološke analize korpusa kot tudi pripravo integriranih kart $\mathrm{z}$ rabo tehnike računalniške kartografije. RMNyA je primeren tudi za primerjave $z$ manjšimi regionalnimi atlasi.

Na izbranih raziskovalnih točkah MNyA in RMNyA so opravljene raziskave današnjega jezika s pomočjo vprašalnikov, zbranih iz vprašanj za oba atlasa, da bi ugotovili spremembe, ki so se pojavile v preteklih petdesetih letih. 